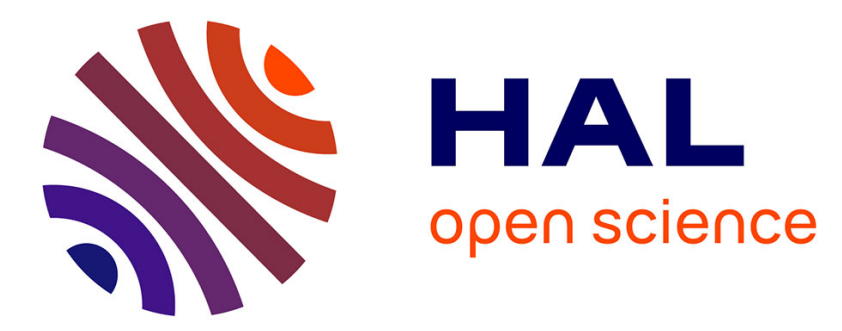

\title{
Vacuum UV broad-band absorption spectroscopy: a powerful diagnostic tool for reactive plasma monitoring
}

G Cunge, M Fouchier, M Brihoum, P Bodart, M Touzeau, N Sadeghi

\section{To cite this version:}

G Cunge, M Fouchier, M Brihoum, P Bodart, M Touzeau, et al.. Vacuum UV broad-band absorption spectroscopy: a powerful diagnostic tool for reactive plasma monitoring. Journal of Physics D: Applied Physics, 2011, 44 (12), pp.122001. 10.1088/0022-3727/44/12/122001 . hal-00604883

\section{HAL Id: hal-00604883 https://hal.science/hal-00604883}

Submitted on 30 Jun 2011

HAL is a multi-disciplinary open access archive for the deposit and dissemination of scientific research documents, whether they are published or not. The documents may come from teaching and research institutions in France or abroad, or from public or private research centers.
L'archive ouverte pluridisciplinaire HAL, est destinée au dépôt et à la diffusion de documents scientifiques de niveau recherche, publiés ou non, émanant des établissements d'enseignement et de recherche français ou étrangers, des laboratoires publics ou privés. 


\title{
Vacuum UV Broad-Band absorption spectroscopy: a powerful diagnostic tool for reactive plasma monitoring
}

G. Cunge, M.Fouchier, M. Brihoum, P.Bodart, M.Touzeau and N.Sadeghi

Laboratoire des Technologies de la Microélectronique, CNRS-LTM, 17 rue des Martyrs, 38054 Grenoble Cedex 09, France

\begin{abstract}
Broad band UV-visible absorption spectroscopy is widely used to measure the concentration of radicals in reactive plasmas. We extended the applicability of this technique to the VUV $(115 \mathrm{~nm}$ to $200 \mathrm{~nm}$ ), the spectral range in which the electronic transitions from the ground state to the Rydberg or pre-dissociated states of many closed shell molecules are located. This gives access to the absolute densities of species which do not, or weakly absorb in the $\mathrm{UV} / \mathrm{visible}$ range. The technique is demonstrated by measuring the densities of $\mathrm{HBr}$ and $\mathrm{Br}_{2}$ molecules in $\mathrm{HBr}$ high-density ICP plasmas.
\end{abstract}

PACs numbers: 52.77.Bn, 52.70.Kz and 33.20.Lg 
Broad band absorption spectroscopy (BBAS) in the UV-visible region is a widely used technique to measure the absolute concentration of radicals in gaseous media. The application domain of this technique is wide, ranging from the detection of atmospheric gases and pollutants ${ }^{1}$ to the measurement of the densities of small polyatomic radicals in reactive plasmas $^{2,3,4,5}$. In the past 10 years, the sensitivity of BBAS has been enhanced by two orders of magnitude thanks to the progress in detection system and to recent availability of extremely stable light sources (UV LEDs) ${ }^{6,7}$. This was necessary to probe reactive plasmas, in which the absorbance by radicals is typically smaller than a few $10^{-3}$. However, BBAS is restricted to the detection of radicals which absorbs light in the UV-visible domain, i.e. often small polyatomic radicals. For instance, the detection of larger, closed shell molecules is impossible and relies on the use of more sophisticated laser absorption techniques in the infrared region $^{8,9,10,11}$ or on mass spectrometry ${ }^{12,13}$. However, many molecules have Rydberg states or pre-dissociated continuums which absorb in the Vacuum-UV (VUV) spectral range. In etching plasmas, examples of relevant molecules that could be detected in the VUV region includes $\mathrm{Cl}_{2}, \mathrm{HBr}, \mathrm{BrCl}, \mathrm{Br}_{2}, \mathrm{HCl}, \mathrm{BCl}_{3}, \mathrm{SiCl}_{4}, \mathrm{SiF}_{4}, \mathrm{CCl}_{4}, \mathrm{SF}_{6}, \mathrm{CH}_{2} \mathrm{~F}_{2}, \mathrm{O}_{2}$. Most of these molecules have no transitions accessible in the UV-visible domain, or the transition probability is not large enough for providing measurable absorption rate in low pressure plasmas. Since the electronic transitions from the ground state to the Rydberg states of molecules often have very large probabilities, the VUV absorption spectroscopy is promising to detect those molecules with a high sensitivity and it should be complementary to the typical UV-visible absorption spectroscopy. However, broad band VUV absorption spectroscopy has not yet been used for probing low pressure reactive plasmas.

Our experimental set up is shown in Fig.1 and has been described in our previous UVBBAS publications ${ }^{14,15}$. We are using an industrial, $50 \mathrm{~cm}$ diameter etching reactor (Advantage ${ }^{\mathrm{TM}} \mathrm{G} 5$ silicon etcher from Applied Materials) designed to etch $300 \mathrm{~mm}$ diameter 
wafers. The light source is a high pressure deuterium $\left(\mathrm{D}_{2}\right)$ lamp (X2D2 from Hamamatsu) that emits a continuum radiation extending from 100 to $400 \mathrm{~nm}$. A VUV grade parabolic mirror produces a collimated, $1 \mathrm{~cm}$ diameter, light beam at $90^{\circ}$ from the incident light. This VUV beam crosses the reactor chamber, through two optical ports (with $\mathrm{MgF}_{2}$ windows) facing each other, at about $5 \mathrm{~cm}$ below the reactor roof on which lies the rf coil used to create the plasma. At the exit of the second window, another VUV grade parabolic mirror focuses the VUV beam onto the entrance slit of a $20 \mathrm{~cm}$ focal length VUV monochromator (Jobin-Yvon H20-UVL), equipped with a 1200 groove/mm VUV grating. With $40 \mu \mathrm{m}$ entrance and exit slit widths, the spectral resolution of the system is about $0.2 \mathrm{~nm}$. The light intensity at the exit slit is converted to an electric signal with a solar blind Photomultiplier Tube (PMT) (R8486 from Hamamatsu) backed with a $10^{6}$ V/A amplifier. The choice of reflective optics instead of lenses is mandatory because in the VUV the wavelength dependence of the focal length of lenses is too strong to ensure a good collimation and focussing of the beam all over the 115$200 \mathrm{~nm}$ range. To discard the strong plasma induced emission, the intensity of the light from $\mathrm{D}_{2}$ lamp is modulated at $115 \mathrm{~Hz}$ with a tuning fork chopper placed before the first parabolic mirror (see Fig. 1) and the signal from the PMT is processed with a lock-in amplifier ${ }^{6}$, whose output is digitalised by an A/D converter and recorded in a computer. The entire optical path (between $\mathrm{D}_{2}$ lamp / reactor input window and between exit window/PMT) is pumped down to $10^{-4}$ Torr by turbomolecular pumps.

To record an absorption spectrum, the wavelength of the monochromator is scanned and the intensity $\mathrm{I}_{\mathrm{T}}(\lambda)$ of the transmitted light after having passed through the $l=50 \mathrm{~cm}$ plasma is acquired. The absorption spectrum is then deduced from the Beer Lambert law:

$$
\frac{\mathrm{I}_{\mathrm{T}}}{\mathrm{I}_{0}}(\lambda)=\exp (-\mathrm{A}(\lambda))
$$


Where $I_{0}(\lambda)$ is the signal recorded in an empty reactor chamber, $A(\lambda)=N l \sigma(\lambda)$ is the absorbance, $\mathrm{N}$ the density of the absorbing species and $\sigma$ the absorption cross section.

Fig.2 shows the absorption spectra of $\mathrm{HBr}$ at different pressures recorded without plasma. $\mathrm{HBr}$ is a closed-shell molecule, with $(4 \mathrm{~s} \sigma)^{2}(4 \mathrm{p} \sigma)^{2}(4 \mathrm{p} \pi)^{4}$ molecular orbital electron configuration in the $\mathrm{X}^{1} \Sigma^{+}$ground state ${ }^{16}$. According to the Nee et al ${ }^{17}$ assignment, the three strongly absorbing peaks of this spectra correspond to the $4 \mathrm{p} \pi \rightarrow 5 \mathrm{~s} \sigma$ electron excitation in the Rydberg states $C{ }^{1} \Pi$ (for 137 and $143 \mathrm{~nm}$ peaks) and $b^{3} \Pi$ (for $150 \mathrm{~nm}$ peak), while the continuum between 154 and $235 \mathrm{~nm}$ results from the $4 \mathrm{p} \sigma \rightarrow \sigma^{*}$ transition into the dissociative $a^{3} \Pi$ and $A^{1} \Pi$ states ( $\sigma^{*}$ is an antibonding orbital). These authors also give the corresponding cross sections, which can be use to deduce the $\mathrm{HBr}$ density from the measured absorbance. However, for a stable gas like $\mathrm{HBr}$, we could directly measure $\mathrm{I}_{\mathrm{T}} / \mathrm{I}_{0}$ ratio at different wavelengths as a function of $\mathrm{HBr}$ pressure (density) in the chamber. This possibility is of prime importance since as seen in Fig.2, the absorbance of transitions to Rydberg states is strongly saturated even at low $\mathrm{HBr}$ densities $(A(\lambda)$ does not vary linearly with $\mathrm{N}$ and is almost saturated for the $143 \mathrm{~nm}$ band). It should be emphasised that each of the observed peaks at 137, 143 and $150 \mathrm{~nm}$ is in reality composed of many rotational lines, having a Doppler width of about $0.25 \mathrm{pm}$ and of non absorbing regions between these lines. As the width of these lines is much smaller than the $0.2 \mathrm{~nm}$ spectral resolution of the monochromator we are using, we can conclude that with the measured absorbance in the range of unity, the absorption on the position of rotational lines is almost total (for more detail see Ref. 4). So, for transitions to the Rydberg states, the medium cannot be considered as optically thin, even at low $\mathrm{HBr}$ density. Fortunately, this non linearity is not an issue since most of the molecules accessible in the VUV are stable (i.e. available as commercial gases): it is thus possible to experimentally determine the relation between the measured $\mathrm{I}_{\mathrm{T}} / \mathrm{I}_{0}$ and the density, shown in 
Fig.2. But for the continuum part of the absorption spectrum, this artefact no more exists and the absorbance becomes proportional to the $\mathrm{HBr}$ density.

Fig. 3 shows the absorption spectrum recorded in 5 mTorr total pressure pure $\mathrm{HBr}$ plasma at $600 \mathrm{~W}$ (without wafer). The absorption spectrum recorded at $1 \mathrm{mTorr} \mathrm{HBr}$ gas (no discharge) is also shown in the same figure. Features corresponding to the $\mathrm{HBr}$ absorption of these two spectra are very similar, indicating that the density of $\mathrm{HBr}$ molecules in the plasma is about $3.10^{13} \mathrm{~cm}^{-3}$. Furthermore, new absorption features are seen in the spectrum recorded in the plasma. These New bands are unambiguously attributed to the absorption by $\mathrm{Br}_{2}$ molecules formed by $\mathrm{Br}$ atoms recombination on the reactor walls ${ }^{18,19}$. VUV absorption from $\mathrm{Br}_{2}$ on a few rotational lines have been observed by the resonance enhanced photo ionization technique and analyzed previously ${ }^{20}$ but to our knowledge, its complete VUV absorption spectrum is missing in the literature. To obtain the absorption spectrum of the $\mathrm{Br}_{2}$ molecule, we subtracted the $\mathrm{HBr}$ contribution from the recorded plasma absorption spectrum. The resultant spectrum is shown in the lower part of Fig.3. Beside the absorption spectrum of $\mathrm{Br}_{2}$ one can distinguish a small contribution from $\mathrm{H}$ atoms at $121.6 \mathrm{~nm}$ (Lyman $\alpha$ ). It is not straightforward to deduce the absolute density of $\mathrm{Br}_{2}$ from this spectrum since for the same reasons than already mentioned for $\mathrm{HBr}$, the absorption on rotational lines of $\mathrm{Br}_{2}$ must be saturated and unfortunately it is not permitted to introduce $\mathrm{Br}_{2}$, which is liquid at room temperature, into the chamber. However, it is possible to produce known amounts of $\mathrm{Br}_{2}$ molecules by mixing $\mathrm{HBr}$ and $\mathrm{Cl}_{2}$ gases, which react totally together to form $\mathrm{HCl}$ and $\mathrm{Br}_{2}{ }^{9,21}$ So, the absorption spectrum recorded at pressure $p$ in an stochiometric mixtures $(2 / 1)$ of $\mathrm{HBr} / \mathrm{Cl}_{2}$ gases, will correspond to the one recorded in a mixture of 2/3.p of $\mathrm{HCl}$ and 1/3.p of $\mathrm{Br}_{2}$. Using this procedure, we were able to obtain the wavelength dependent absorption spectra of $\mathrm{Br}_{2}$ at different pressures. So, the absorbance of $\mathrm{Br}_{2}$ could be calibrated on an absolute scale ${ }^{22}$. It leads to a $\mathrm{Br}_{2}$ density of $1.45 \times 10^{13} \mathrm{~cm}^{-3}$ at $600 \mathrm{~W}$ rf power (Fig.3). 
Fig.4 shows the rf power dependence of the $\mathrm{HBr}$ and $\mathrm{Br}_{2}$ densities in a 5 mTorr $\mathrm{HBr}$ plasma without etching substrate. With increasing rf power, the electron density and hence the dissociation fraction of $\mathrm{HBr}$ molecules increase. Furthermore, since the gas temperature also increases with the electron density ${ }^{23}$ and since the pressure is maintained at 5 mTorr, the observed decrease of the $\mathrm{HBr}$ density when the rf power increases (Fig.4) can also partially due to the neutral depletion ${ }^{24}$. In contrast, when the rf power is increased, the dissociation fraction of $\mathrm{HBr}$ increases and more $\mathrm{Br}$ atoms are available to recombine on the reactor walls leading to a higher $\mathrm{Br}_{2}$ density. However, above $200 \mathrm{~W}$, an equilibrium is reached between the dissociation of $\mathrm{Br}_{2}$ by electron impact and its production by recombination on the reactor walls and the observed decay of $\mathrm{Br}_{2}$ density must also be due to the neutral depletion by gas heating.

In conclusion, VUV absorption spectroscopy is a simple and powerful technique to measure the density of stable molecules in reactive plasmas. Giving access to novel species, it is complementary to the typical absorption spectroscopy in the UV-visible region. Furthermore, owing to the large strength of the transitions in the VUV region, the technique appears to be highly sensitive. It follows that extremely low densities can be measured with a good accuracy. The drawback is that many absorption bands are saturated. However, this is not an issue since the molecules that can be detected are often stable gases, for which the absorbance can be directly calibrated by filling the reactor with known pressure of these gases. The detection limit of the technique can be drastically improved if the PMT detector is replaced by a VUV sensitive Diode-Array or a CCD detector. This will eliminate the nonquantum noise of the sequential scan of the monochromator and would also significantly reduce the data acquisition time. Information we are reporting in this paper are essential for a better understanding of etching processes in $\mathrm{HBr}$-based plasmas, which are widely used in 
microelectronic industry to etch silicon, and for which information available in the literature are extremely sparse ${ }^{8}$.

Acknowledgment: This work was supported (partially) by the European EUREKA/CATRENE program in the frame of the CT206 UTTERMOST project 


\section{References}

1 F. Xu, Z. Lv, Y.G. Zhang, G. Somesfalean, and Z.G. Zhang, Appl. Phys. Lett. 88, 231109 (2006).

M.A. Childs, K.L. Menningen, P. Chevako, N.W. Spellmeyer, L.W. Anderson, and J.E. Lawler, Phys. Lett. A 171, 87 (1992).

J.P. Booth, G. Cunge, F. Neuilly, and N. Sadeghi, Plasma Sources Sci. Technol. 7, 423 (1998).

M. Kogelschatz, G. Cunge, and N. Sadeghi, J. Phys. D: Appl. Phys. 37 (14), 1954 (2004).

$5 \quad$ P. Chabert, G. Cunge, J.P. Booth, and J. Perrin, Appl. Phys. Lett. 79, 916 (2001).

6 G. Cunge, D. Vempaire, M. Touzeau, and N. Sadeghi, Appl. Phys. Lett. 91, 231503 (2007).

D. Vempaire and G. Cunge, Appl. Phys. Lett. 94, 21504 (2009).

S. Chou, D. Baer, and K. Hanson, J. Vac. Sci. Technol. A 19 (2), 477 (2000).

S. Kim, P. Klimecky, J.B. Jeffries, F.L. Terry, and R.K. Hanson, Meas. Sci. Technol. 14, 1662 (2003).

J. Röpcke, L. Mechold, M. Käning, W.Y. Fan, and P.B. Davies, Plasma Chem. Plasma Process. 19, 395 (1999).

F. Hempel, V. Artyushenko, F. Weichbrodt, and J. Röpcke, J. Phys.: Conf. Ser. 157, 012003 (2009).

M. Kogelschatz, G. Cunge, and N. Sadeghi, J. Vac. Sci. Technol. A 22, 624 (2004).

H. Singh, J.W. Coburn, and D.B. Graves, J. Vac. Sci. Technol. A 17 (5), 2447 (2000).

G. Cunge, D. Vempaire, R. Ramos, M. Touzeau, O. Joubert, P. Bodart, and N. Sadeghi, Plasma Sources Sci. Technol. 19, 34017 (2010). 
G. Cunge, D. Vempaire, and N. Sadeghi, Appl. Phys. Lett. 96, 131501 (2010). G. Herzberg, Molecular Spectra and Molecular Structure I. Spectra of diatomic molecules, 2nd edition. (1950).

J.B. Nee, M. Suto, and L.C. Lee, J. Chem. Phys. 85 (9), 4920 (1986).

18

G. Cunge, R.L. Inglebert, O. Joubert, L. Vallier, and N. Sadeghi, J. Vac. Sci. Technol. B 20 (5), 2137 (2002).

G. Cunge, O. Joubert, and N. Sadeghi, J. Appl. Phys. 94 (10), 6285 (2003).

20

T. Ridley, D.A. Beattie, M.C.R. Cockett, K.P. Lawley, and R.J. Donovan, Phys.

Chem. chem. Phys. 4, 1398 (2002).

21

H. Xiao, Z. Wang, J. Xiao, and Z. Chen, Science in China (Series B) 44 (3), 283 (2001).

M. Brihoum, G. Cunge, and N. Sadeghi, To be published (2011).

23

G. Cunge, R. Ramos, D. Vempaire, M. Touzeau, M. Neijbauer, and N. Sadeghi, J. Vac. Sci. Technol. A 27 (3), 471 (2009).

M. Shimada, G.R. Tynan, and R. Cattolica, J. Appl. Phys. 103, 033304 (2008). 


\section{Figure Caption}

Fig.1 : Schematic of the experimental set-up (top view).

Fig.2 : Absorption spectra of $\mathrm{HBr}$ gas at 5, 10 and 20 mTorr pressures. The insert shows in more detail the absorption bands to the Rydberg states.

Fig.3 : Upper part: absorption spectra of a 5mTorr / $600 \mathrm{~W} \mathrm{HBr}$ plasma and absorption spectra of 1 mTorr $\mathrm{HBr}$ gas (no plasma). Lower part: fractional absorption of $\mathrm{Br}_{2}$ in the plasma obtained by subtracting the $\mathrm{HBr}$ contribution from the plasma spectrum

Fig.4: Absolute densities of $\mathrm{HBr}$ and $\mathrm{Br}_{2}$ as a function of the RF power in a 5 mTorr pure $\mathrm{HBr}$ plasma 
Cunge et al, APL

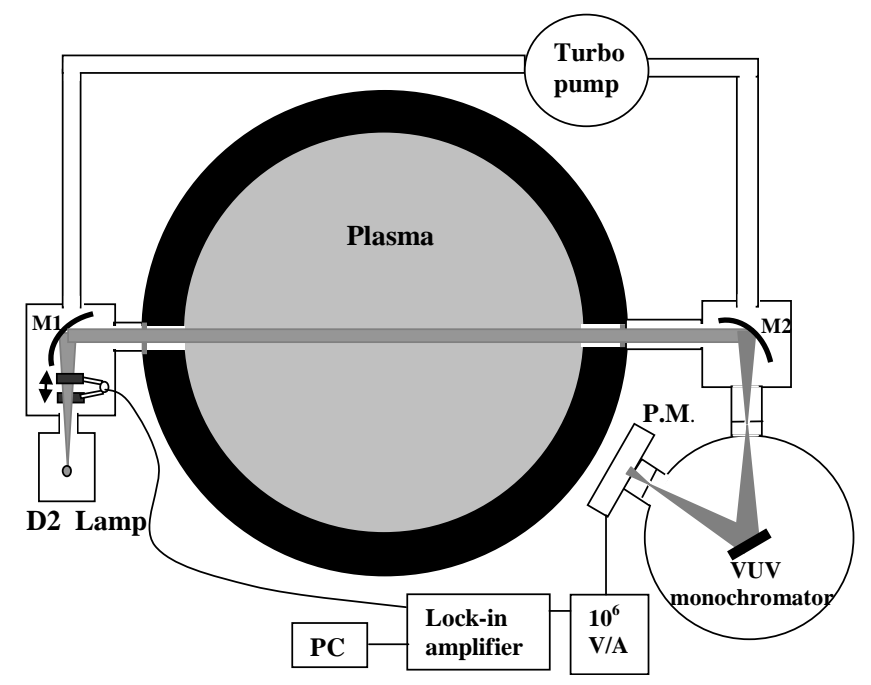

Fig.1 
Cunge et al, APL

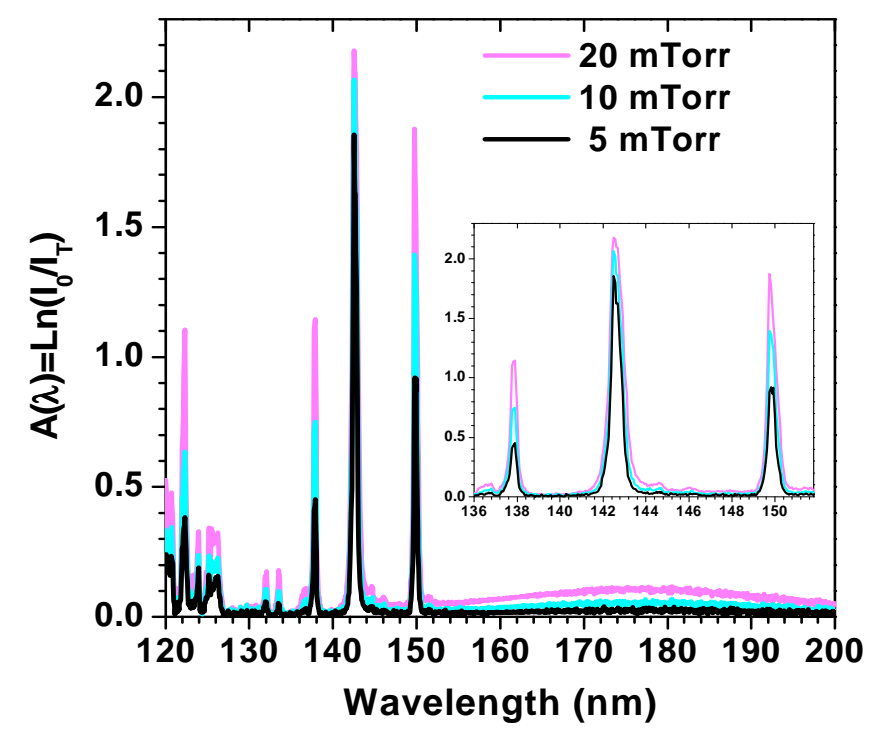

Fig.2 
Cunge et al, APL

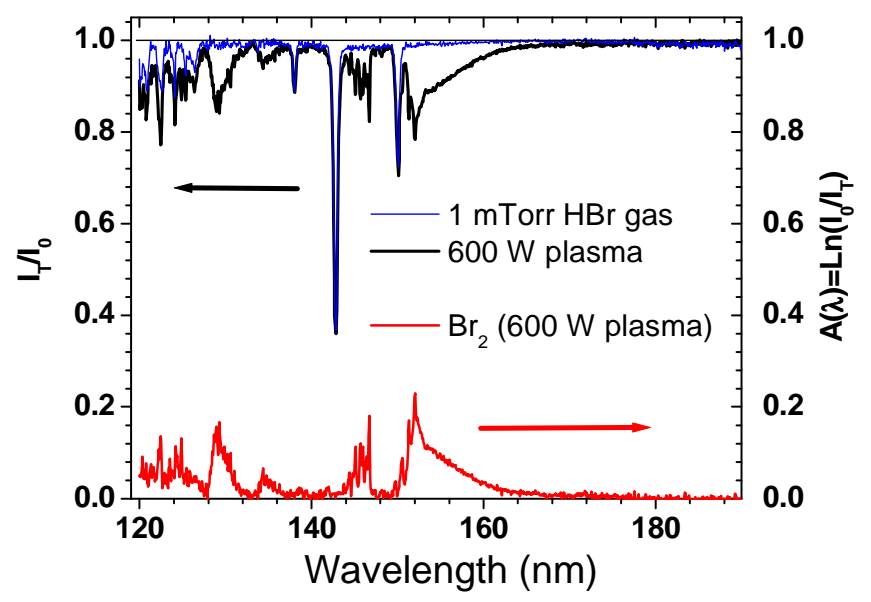

Fig.3 
Cunge et al, APL

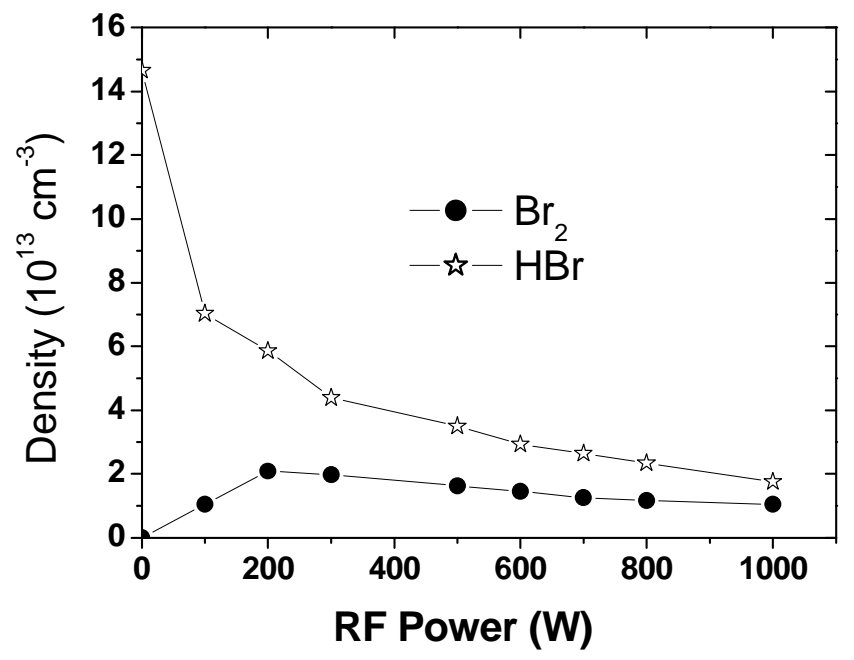

Fig.4 